\title{
FILOLOGIA E CAMPO HISTORIOGRÁFICO (OU UMA PEQUENA CRÍTICA AO MÉTODO)
}

Marcello Moreira

(D) https://orcid.org/0000-0001-6827-2772

Como citar este artigo: MOREIRA, M. Filologia e campo historiográfico (ou uma pequena crítica ao método). Todas as Letras - Revista de Lingua e Literatura, São Paulo, v. 23, n. 1, p. 1-12, jan./abr. 2021. DOI 10.5935/1980-6914/eLETDO2114310

Submissão: fevereiro de 2021. Aceite: fevereiro de 2021.

Ao avaliar cada objeto, considera-o já em via de dissolução, no ato de se transformar e quase de apodrecer ou desfazer-se, ou então considera que cada coisa nasceu quase para morrer (Marco Aurélio, X, 18).

Cars, bruns teinz motz entrebesc Pensius pensanz (Raimbaut d'Aurenga).

Resumo: O objetivo deste artigo é abordar os métodos filológicos a partir do estabelecimento de uma relação crítica entre a filologia e a historiografia.

Palavras-chave: Filologia. Historiografia. Crítica. Métodos filológicos. 


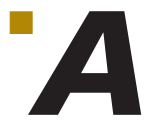

filologia é uma das mais antigas disciplinas históricas, que, no entanto, desde meados do século XIX, nunca mirou o próprio rosto no espelho de Clio e cuja historicidade nunca foi reconhecida por aqueles estudiosos que deram a si próprios o nome de filólogos ${ }^{1}$. Os textos ditos "literários", objeto de estudo da filologia, deveriam ser o campo de confronto sistemático entre filologia e historiografia, mas a prática filológica brasileira e portuguesa, de cunho neolachmanniano, sendo antes de mais nada um fato de doutrina, pensa o fazer história próprio dos filólogos como o resultado definitivo de uma subsunção da história e da historiografia na própria prática filológica cujo telos doutrinal anistórico é a recuperação do texto dito "genuíno"2 (Esse pensamento filológico, formulado em pleno século XIX, transfere para o âmbito da história um modo de pensar que nos é hoje em dia estranho, pois faz crer em tendências ao mesmo tempo inerentes e finalistas, que animam o texto e em que somente pode haver coerência à medida que este atenda crescentemente a um fim ${ }^{3}$ ). $\mathrm{O}$ que aqui se diz tem caráter diagnóstico, mas, também, infelizmente, prognóstico, pois não vemos filólogos questionando sua prática, tomando-a como objeto de reflexão sistemática. Durante muito tempo, pensou-se que o fazer filológico tivesse como condição primeira a existência de imensas jazidas documentais a serem exploradas e que a matéria-prima do trabalho filológico fossem os textos "literários", quando, na verdade, o método é o primeiro filão a ser escavado, embora a prática consuetudinária entre nós tenha sido a de se apropriar do cascalho de tempos idos pensando-o, no entanto, como espécie de pedra filosofal. Pode-se dizer que a filologia que hoje em dia se pratica no Brasil e em Portugal se circunscreva ao que se chama de "ciência normal"4 e que os procedimentos críticos que balizam o fazer filológico sejam totalmente paradigmáticos como no-los define Kuhn (2017). Carlo Ginzburg, ao falar da relação entre "paradigma" e "historiografia", assevera que essa é uma "disciplina pré-paradigmática"; mas haveria um outro modo de existência possivel para a historiografia? Ela não pode ser paradigmática se sua condição de existência é a de justamente empreender uma crítica sistemática das possibilidades do fazer histórico, em que se subsumem teorias, métodos e procedimentos postos

1 A despeito de haver congressos dedicados à história da filologia, os trabalhos apresentados nas sessões que os constituem normalmente valorizam propostas normativas, que prescrevem o que a filologia deveria ser, definindo-a a partir de manuais estrangeiros ou em português que circunscrevem o escopo dessa disciplina, para, somente em seguida, enquadrar o objeto de que se trata particularmente na definição prévia que o subsome. Só assim, parece-me, creem os filólogos que as edições por si preparadas produzem efeitos de real "como um acordo entre as representações adquiridas e os códigos admitidos ao leitor e ao escriturário", que não costumam contestar (GOULEMOT, 1996, p. 108). Esses trabalhos têm outra característica: são extremamente descritivos, conquanto essa descrição não empreenda a crítica da historicidade do que descreve. Em âmbito lusófono, a par de uma bibliografia doutrinal escassa, há, ao lado do que se poderia chamar de "normatividade da prática", fundada nessa bibliografia doutrinal, uma outra prática, que não pode contudo se opor à teoria como corpo de conhecimento filológico já acumulado inclusive pela prática editorial nela fundada, pois que incapaz de explicitar sobre que bases opera; pode-se dizer que pelo menos no Brasil há majoritariamente a submissão desse capital acumulado de prática crítica à teoria, não havendo espaço, portanto, para a pesquisa filológica conseguir evitar a pressão normativa de princípios estabelecidos sobre a prática. Sabemos que o pensamento filológico no Brasil está presente na pouca diversidade empírica da pesquisa filológica, mas na forma de "opiniões" diferenciadas e até mesmo contraditórias, que não se elevam a princípios, categorias ou proposições, e que se ignoram ou propositadamente se calam. Nossa investigação do pensamento filológico, a par de constatar sua diversidade, visa a historicamente entender os limites da produtividade de propostas normativas e da diversidade empírica das práticas, elencando os argumentos e ajuizando-os.

2 Dentre as definições de "texto genuíno" que se encontram nos manuais de crítica textual publicados no Brasil, a mais recorrente em estudos filológicos é aquela que comparece no manual de Segismundo Spina, 1977, p. 23) e incansavelmente citada toda vez que se tem de definir os fins a que visa uma edição crítica: "Um texto pode ser legítimo, autêntico, mas não genuíno. Suponhamos a $1^{a}$ edição de uma obra: ela é autêntica, legítima (isto é, não é falsa) porque saiu em vida do autor e foi supervisionada por ele. Acontece que nem sempre a $1^{\text {a }}$ edição corresponde ao desejo do autor, que nela encontra falhas e coisas que já não condizem com o seu espírito. Assim: uma edição ne varietur é uma edição definitiva conforme os desejos do autor; talvez seja ela a $4^{a}$ edição. Esta $4^{a}$ edição é genuína, mas as três primeiras não o são, embora sejam autênticas, legítimas".

3 Spina (1977, p. 32).

4 Ver Ginzburg (1991a, p. 171). 
sob contínuo escrutínio, de que deriva serem os paradigmas e sua caducidade objeto mesmo da historiografia, pois esta escrutina suas determinações manifestas. Se o campo historiográfico se beneficiou desde a segunda metade do século passado de uma proximidade crescente com a antropologia, de que derivaram novos temas de pesquisa, e, sobretudo, novos modelos cognitivos, de que decorreu o fim da ilusão etnocêntrica - "o que tornou insustentável a ideia de uma história universal” (GINZBURG, 1991a, p. 173) -, esse contato e os benefícios dele advindos parecem não ter chegado ao campo filológico, cujo etnocentrismo de base é condição da própria prática filológica. Dois dos avatares da doutrina filológica de base neolachmanniana, Segismundo Spina e Ivo Castro, respectivamente do Brasil e de Portugal, pregam do modo que segue o telos disciplinar:

Um texto pode ser legítimo, autêntico, mas não genuíno. Suponhamos a $1^{a}$ edição de uma obra: ela é autêntica, legítima (isto é, não é falsa) porque saiu em vida do autor e foi supervisionada por ele. Acontece que nem sempre a $1^{a}$ edição corresponde ao desejo do autor, que nela encontra falhas e coisas que já não condizem com o seu espírito. Assim: uma edição ne varietur é uma edição definitiva, saída conforme os desejos do autor; talvez ela seja a $4^{a}$ edição. Esta $4^{a}$ edição é genuína, mas as três primeiras não o são, embora sejam autênticas, legitimas (SPINA, 1977, p. 23) ${ }^{5}$.

Se se quiser, estabelecer um texto consiste em preparar, a partir de um seu exemplar cuidadosamente escolhido, uma cópia em que alternam a reprodução dos elementos gráficos atribuiveis ao autor (transcrição) e a substituição dos elementos reputados não-autorais (erros) pelos seus correspondentes conjecturadamente originais (emenda) (CASTRO, 1995, p. 515).

Se o método proposto por Segismundo Spina e Ivo Castro empreende, pela prática sistemática de substituição de "elementos reputados não-autorais" por seus correspondentes "conjecturadamente originais", a recuperação do texto ajuizado "genuíno", ele institui previamente à operação crítico-filológica o binômio "erro" versus "emenda", que só tem sentido perante a genuinidade que é, por seu turno, pré-constituída a esse binômio que dela deriva. Mas qual seria o objetivo final de se empreender a sistemática substituição do que se considera "erro" pelas correlatas "emendas"?6 . A redução das diferenças entre texto supostamente autoral (que não se identificaria a nenhum dos testemunhos constitutivos da tradição textual, pois se tal identificação fosse possivel, o procedimento crítico de restitutio seria descartável) e texto filologicamente reconstituído visa,

50 mesmo diz Ivo Castro (1997a, p. 608) em verbete de Biblos: "como editar um texto, quando não há um original único, mas diversos, correspondentes a etapas sucessivas da gênese do texto? Como dar conta da variação entre esses originais e como fixar o texto crítico? Na maioria das situações, o texto crítico reproduzirá o estado em que o autor deixou o seu texto, da última vez que o trabalhou; entre todos os originais, esse tem a autoridade acrescida de ser o único que o autor não pôs em causa por meio de uma revisão". Essa ideia se encontra reforçada em outro estudo publicado em 1997 por Ivo Castro, belo ensaio sobre a fatura de uma edição crítica de obras de José Tavares de Macedo, preservadas em manuscrito autógrafo, em que a colação empreendida entre vários estados variantes de cada uma das duas obras editadas atendeu à seguinte demanda: "determinação da versão mais recente" para "estabelecimento do texto crítico", o que evidencia estar implicada no procedimento analítico a ideia de telos, sendo, por conseguinte, a versão mais recente sempre melhor, contrariamente à chamada filologia do manuscrito ausente, em que cada cópia implica deterioração do estado textual inaugural, ambas sobredeterminantes da prática filológica (CASTRO, 1997b, p. 403-409).

6 Ivo Castro (1997a, p. 606), no verbete "filologia", publicado em Biblos, assevera mais uma vez que, quando da fatura de edições críticas baseadas em tradições textuais politestemunhais, alternam dois procedimentos de base, ou seja, "transcrição" e "emenda"; esta última só tem sentido diante da crença de que tradições textuais são sempre "conjuntos formados pelas sucessivas cópias de um texto, produzidas ao longo do tempo e cada vez mais afastadas, na forma e no sentido, do texto original do autor", sem o quê, não seria preciso haver emendas. 
em última instância, a "habilitar qualquer leitor a extrair do texto a exacta interpretação que o autor tencionou" (CASTRO, 1995, p. 515). Por ora, é preciso apenas dizer que a possibilidade de submeter todas as tradições textuais, que são objeto da crítica filológica, aos mesmos procedimentos metódicos, como a substituição sistemática de "erros" por "emendas", implica supor uma absoluta identidade entre essas tradições que autorize sua subsunção aos mesmos procedimentos crítico-metódicos; as tradições, se documentos, e o são, deveriam ser passíveis de seriação, pois são pertencentes a um mesmo gênero, de que sobressairiam os elementos redundantes, com exclusão dos discrepantes e singulares, julgados desimportantes ou mesmo indiferentes. A serialização documental é fundamental para setores da pesquisa histórica que dependem do quantitativismo de longo período para a obtenção de resultados pertinentes, como é o caso, entre muitos, da história dos preços, daquela dos movimentos de produção e da que tomou como objeto as crises demográficas (CHARTIER, 1996). Mas o que difere o quantitativismo histórico da crítica textual é que ele recolhe dados - como o número de nascimentos e óbitos em um dado recorte da duração e do espaço, extraídos de um mesmo gênero de documentos, passiveis de serialização - algarísmicos, que demandam posterior interpretação e que podem revelar para o historiador, por exemplo, mutações estruturais das crises demográficas europeias, "das crises catastróficas de mortalidade do cruel século XVII às crises de 'morbilidade' - menos pesadamente malthusianas - do século XVIII" (GINZBURG, 1991b, p. 171), sem que "haja" uma ou outra previamente à serialização e ao censo documental ${ }^{7}$. No caso da crítica textual ao tempo em que se fala da unicidade de cada tradição, tratam-se todas elas como unidades homólogas, e a aplicação a todas de um mesmo método e de idênticos procedimentos críticos visa apenas a nelas achar o que se sabe haver nelas, a corrupção da obra de um deus absconditus, o autor ${ }^{8}$. O método neolachmanniano praticado no Brasil e em Portugal produziu seus dados previamente à análise documental e quando depara com o que já sabe ali estar, pensa equivocadamente que encontrou o fio de Ariadne, que é, na verdade, o baraço da análise fisiognomômica ${ }^{9}$.

7 Roger Chartier (2004, p. 129), em um artigo em que analisa a contribuição de Michel Foucault à renovação do campo historiográfico, afirma que a serialização documental em história, ao construir séries homogêneas, e, ao mesmo tempo, distintas, possibilita a determinação das "descontinuidades" e a situação das "emergências", o que teria motivado Michel Foucault a considerar, em Ordem do discurso, "as tabelas de preços de produtos, as certidões notariais, os registros paroquiais, os arquivos portuários", pois "à distância da 'história filosófica' e da análise estrutural, a história que trata serialmente os arquivos maciços [...] não é nem o relato contínuo de uma história ideal, nem a maneira hegeliana ou marxista, nem uma descrição estrutural sem acontecimentos". Cita, em seguida, passagem de Ordem do discurso, em que se explicita como a história serial promove a compreensão das condições de aparecimento do evento: "É claro, há muito tempo a história não procura mais compreender os acontecimentos por meio de um jogo de causas e efeitos na unidade informe de um grande devir, vagamente homogêneo ou estritamente hierarquizado; mas não é para resgatar estruturas anteriores e estrangeiras, hostis ao acontecimento. É para estabelecer as séries diversas, entrecruzadas, frequentemente divergentes, mas não autônomas, que permitem circunscrever o 'lugar' do acontecimento, as margens de sua eventualidade, as condições de seu aparecimento" (p. 129).

8 Carlo Ginzburg (1991b, p. 215), em estudo em que discute uma analogia possível entre ekphrasis e citação, se pergunta "se os juízos do historiador implicam algum princípio de generalização que possa fundamentar o carácter científico da história". Pode-se dizer por ora que na filologia dos lachmannianos e neolachmannianos foram princípios de generalização, creu-se, que tingiram essa filologia de um suposto caráter científico, bem ao gosto do século XIX em que ela nasceu.

9 Essa fisiognomonia faz recordar vários procedimentos de natureza tautológica, alguns recorrentes em estudos históricos e criticados ferozmente por March Bloch em seu Apologie pour I'histoire, mas não só, pois Carlo Ginzburg (1991c, p. 208), em belo artigo em que discute analogias entre inquisidores e antropólogos, nos diz que, quanto aos primeiros, os documentos por eles produzidos, em que registravam o que extraíam dos réus, têm normalmente um caráter monódico, "na medida em que as respostas dos réus não eram mais do que o eco das perguntas dos inquisidores". Os filólogos neolachmannianos, em sua busca do texto tencionado pelo autor, extraem da tradição a confissão que sabem ela sempre acabará por pronunciar, conquanto não saibam - e nesse sentido são mais ingênuos do que os antigos inquisidores - que ela na maior parte dos casos o faz a contragosto, a contrapelo de sua historicidade. Essa confissão, objetivada no próprio texto crítico, também se faz presente no discurso crítico sobre a obra, sem que o filólogo se aperceba de que "'qualquer discurso indirecto'", como dizia Jakobson, "é uma apropriação e uma remodelação de quem cita" (p. 209). Mas essas apropriações e remodelações não se restringem, por necessidade, ao discurso indireto, podendo dar-se também no discurso direto quando apropriado, e, por consequência, remodelado de várias 
A filologia de que falamos não compreendeu ainda que por mais que se esforce, não é possível a constituição de uma "objetividade histórica", e que, inclusive, "A incompletude da objetividade histórica permite manter em debate a herança histórica para as gerações futuras em uma indefinida busca de sentido" (DOSSE, 2009 , p. 20). Ivo Castro (1995, p. 516) fala de uma disponibilização de instrumentos críticos, no âmbito da prática filológica, que assumiria a feição de uma autocrítica e que conferiria ao campo filológico sua força: mas de que instrumentos críticos fala ele e de que autocrítica, se os instrumentos críticos são de caráter circular e sua autocrítica se reduz à redundância? Se concordamos com Ivo Castro (1995, p. 516) quando assevera que "Nenhuma edição crítica é mais que uma 'proposta de trabalho', nenhuma encerra definitivamente a forma e a significação de um texto", entendemos que o caráter precário de toda edição deriva do fato de sempre se poder formular hipóteses mais verossímeis historicamente para explicar uma tradição textual, de que deriva que a historicidade da tradição pode implicar a precariedade da edição pela precariedade do método que a operou, desafeto a essa mesma historicidade. Se a crítica textual lida com tradições manuscritas de caráter poético, isto é, ficto, a sua desalienação crítica tem por base operar a re-historicização da poética e a re-espacialização das práticas, considerando-se os condicionamentos culturais particulares de cada costume poético, próprio de cada gênero ${ }^{10}$. Como dizia Paul Zumthor (2014, p. 16), "nessa tarefa de desalienação crítica, o que tenho de eliminar logo é o preconceito literário". Se nossa crítica da filologia de base lachmanniana e neolachmanniana implica sempre um retorno a livros seminais do campo filológico, a citações, não o faz com o objetivo único de sancionar determinada reflexão, mas visa a sobretudo "demonstrar que uma resposta já tornada clássica não mais se revela satisfatória, que essa própria resposta fez-se novamente histórica" (JAUSS, 1994, p. 9), ou seja, que a historicidade da questão revelou-se historicamente impertinente diante da historicidade do objeto que a questão objetivava elucidar, sendo o estudioso obrigado a repropô-la. Mas voltemos por ora a um excerto do artigo de Ivo Castro que tem sérias implicações para uma reflexão sobre os métodos filológicos e que já apresentamos ao leitor. Se, como nos diz Ivo Castro, a preparação do texto crítico tem por finalidade "habilitar qualquer leitor a extrair do texto a exacta interpretação que o autor tencionou”, essa proposição de princípio, conquanto refira um lugar comum dos estudos literários, caro, sobretudo, aos teóricos da recepção, o "leitor", mal chega a tangenciá-lo, pois não leva em conta suas modalidades históricas - por exemplo, "discreto" ou "vulgar", categorias da legibilidade em parte da Europa letrada dos séculos XVI e XVII, que indiciam grupos leitores (HANSEN, 2006, p. 85-109) - e muito menos “a

formas (para uma demonstração dos procedimentos de apropriação e remodelação de discursos diretos, ver a profícua análise de The raven, de Edgar Allan Poe, levada a termo por Jakobson (1964), em Langage en opération.

10 A filologia dos lachmannianos e dos neolachmannianos ainda se atém a um princípio historiográfico dessueto, criticado por muitos historiadores do século passado, matéria da aula inaugural de Lucien Febvre no Collège de France: "A história faz-se com textos". A filologia praticada no Brasil e em Portugal não ajuíza importante o estabelecimento de relações entre tradição textual e costume poético, elidindo de seu campo de estudo o que poderíamos chamar "prática", em movimento que contraria toda a tradição de pensamento historiográfico do século XX, que culminaria em obras da importância da de Michel de Certeau. Lucien Febvre, em sua aula inaugural no Collège de France, já empreendia a crítica da história baseada em textos, contrapondo-a àquela outra que, renovada por novos métodos oriundos de campos como economia e geografia humana, passava a ter nas técnicas e práticas elementos sem os quais se permanecia tateando sem nada encontrar de preciso. Qual a decorrência de se persistir em uma história e em uma filologia que se faz só com textos? Para aquela história que se renovou em contato com a geografia humana, por exemplo, eis a perda redundante do pôr de lado técnicas e práticas: "A história faz-se com textos: e de repente parecia evaporar-se a observação penetrante dos sítios, a percepção aguda das relações geográficas próximas ou longínquas, o exame das marcas deixadas na terra humanizada pelo labor obstinado das gerações [...]" (FEBVRE, 1989, p. 17). 
espessura das determinações particulares" (ZUMTHOR, 2014, p. 25) próprias de todo ato de ler ${ }^{11}$. Ao mesmo tempo, essa proposição não reconhece a polissemia do texto poético e elide a compreensão da leitura como efetuação de virtualidades significantes (GOULEMOT, 1996, p. 108). É preciso ponderar um problema histórico que se faz presente em tal asserção ou proposição, pois se o filólogo consegue atualizar o sentido como o autor o teria feito, isso se dá por necessidade, por ser ele capaz de, atendendo a um princípio fundamental da escrita da história do século XIX, anular-se ante seu objeto, permitindo que ele se apresente com total objetividade, com evidente abstração do ponto de vista presente. Mas seria isso possivel? Há um outro problema implicado na proposição de Ivo Castro, a saber: embora tenhamos manuscritos diante de nós quando nos propomos realizar a edição crítica de poemas trovadorescos, não nos perguntamos se tais poemas foram feitos para ser lidos, o que implica pôr em xeque a escritura como meio de sua publicação; os filólogos, como muitos etnólogos criticados por Pierre Bourdieu, cometem frequentemente um erro em sua relação com as coisas que descrevem, notadamente em todos os rituais, "um erro que consiste em ler as práticas (como a performance) como se se tratassem de escritos" (BOURDIEU; CHARTIER, 1996, p. 232), conquanto possam ser delas uma espécie de resíduo. Paul Zumthor (2014, p. 26), valendo-se de proposições de Hans Robert Jauss, reconhece que todo ato de leitura "modifica de alguma maneira o objeto proposto pelo autor, porque não há homologia [...] entre as competências em jogo (escrever, ler)", de que resulta ser impossivel esperar que o leitor, seja ele quem for, extraia "do texto a exacta interpretação que o autor tencionou". Se Ivo Castro insere o leitor ao final do processo de fatura de uma edição crítica, ele o faz para designar mais uma operação abstrata do que o "leitor lendo, operador da ação de ler" (ZUMTHOR, 2014, p. 28) ${ }^{12}$; mas a asserção de Ivo Castro acima citada tem ainda uma outra implicação ou desdobramento, pois se podemos cindi-la em dois polos, sendo o leitor um deles - pois a ele caberia, como dissemos, extrair do texto editado pelo filólogo a exata significação produzida pelo autor ao tempo em que compunha a obra, significação essa que o autor sempre reproduziria idêntica a si mesma toda vez que, como leitor, lesse sua obra ${ }^{13}-$, o

11 Em estudo publicado em Santiago de Compostela, parte de livro em que se homenageia Ivo Castro, João Dionísio (2013, p. 126), ao fazer menção à monografia que Ivo Castro escreveu sobre o poeta Jerônimo Baía, um dos primeiros resultados de sua longa pesquisa textual, assevera que ela é uma averiguação filológica por excelência, pois "tinha como objectivo propor uma representação do texto tão próxima quanto possível do que foi escrito pelo autor", asserção essa que replica a definição dos fins a que visa uma edição crítica tal como propostos por Ivo Castro em vários de seus escritos.

12 Não se pode conciliar em um estudo como o nosso uma posição crítica, em que práticas e objetos dessas práticas têm papel destacado, que valoriza a conjunção entre filologia e bibliografia, em seus vários ramos constitutivos, com qualquer tipo de posição idealista, como, por exemplo, a de Krystoff Pomian (1998, p. 73), que concebe como ideais "obra", "autor" e "leitor": "A obra literária existe fora do tempo e do espaço, pois, sempre e em toda a parte, ela conserva-se idêntica a si mesma. Neste sentido é uma entidade ideal. [...] Na qualidade de entidade ideal, a obra literária só requer duas pessoas: o narrador que a cria e o leitor a quem é dirigida e que é apenas um leitor virtual. Um e outro têm uma existência tão ideal como a própria obra, e é unicamente a obra que permite encontrá-los".

13 Essa hipótese, pois assim ela é por nós apresentada, se nos configura impossivel, pois como o demonstraram os teóricos da recepção e também Paul Zumthor (2014, p. 57), os interstícios a preencher (Lehrstellen), quando de toda ação leitora, só são preenchidos pela intervenção de uma vontade externa, que, no entanto, depende de um campo dêitico particular: "Um aqui-eu-agora jamais exatamente reproduzível. Quando se fala, como já o fiz, da reiterabilidade própria da poesia, essa reiterabilidade não incide sobre a estrutura do campo dêitico, mas no fato de que haverá sempre um campo dêitico particular". Essa posição interpretativa se choca frontalmente com aquela outra defendida por Ivo Castro e que é excelentemente resumida por Krystoff Pomian (1998, p. 87), como segue: "A forma visível conferida à obra é, nesta perspectiva (psicologista ou espiritualista), secundária; o essencial é o projeto que ela encarna. Para o compreender, é pois necessário cotejá-lo com o projeto do seu autor. O leitor, o espectador ou o ouvinte acede a essa compreensão quando consegue introduzir, por assim dizer, em si próprio, os traços da personalidade do autor expressos na sua obra, quando consegue elevar-se desse modo à sua altura, na medida do possível, e recriar em si próprio o projeto que era o seu. Um tal método de estudo da cultura, o único válido, recebe o nome de hermenêutica. Os objetos que privilegia, desde que a forma visível das obras parece ser ali o menos importante, são textos, sobretudo literários e filosóficos. Um historiador de cultura exemplar é sobretudo, senão exclusivamente, um filólogo". Esse postulado ou crença é complementado de fato por aquele outro, característico da metafísica filológica oitocentista, que preconiza encontrar-se 
outro, sem sombra de dúvida o mais importante, o "autor", implica também muitos problemas. Ivo Castro supõe que um certo número de textos ou que um único texto seja passivel de ser atribuído a um indivíduo particular, dotado de um nome próprio e de uma correlata biografia, e que, "a partir da leitura desse texto primeiro ('a obra de Foucault' [por exemplo]), seja legítimo produzir um outro discurso em forma de comentário" (CHARTIER, 2004, p. 123), que, enquanto tal, atualize o sentido tencionado pelo "autor"; sua proposição assenta sobre a crença de que a "unidade da obra" se justifique pela existência de uma correlata "unidade de expressão", que, ao desenrolar-se no tempo, origina de si mesma modulações que são correlatas daquelas do fio biográfico, também ele tecido no tempo. Há aqui o que se poderia denominar uma "epistemologia da coincidência imediata ou da transparência" entre "o discurso e o real" (CHARTIER, 2002, p. 160), que anima a tradição filológica derivada de Karl Lachmann desde meados do século XIX. O texto literário editado pelo filólogo, por seu turno, é pensado como um correlato do "evento" e é sempre marcado, para o pensamento filológico de base neolachmanniana, por sua originalidade (ou causalidade), como se a origem imprimisse uma marca, tupos, indelével, que se faz presente no "texto" mesmo antes que se dê o advento do "evento", marca essa que cabe a procedimentos como o da lectio difficilior potior ${ }^{14}$ identificar $^{15}$. Nesse

a poesia "atemporalmente presente no texto literário", o que possibilita que seu significado objetivo, cunhado de forma definitiva, seja "eterna e imediatamente acessível ao intérprete" (JAUSS, 1994, p. 35).

14 Uma bela pesquisa sobre o conceito lectio difficilior potior fundar-se-ia no escrutínio de sistemas de percepção e apreciação implicados na escolha de uma dada lição, e no correlato das emoções sentidas diante de uma dada estrutura do texto poético, que permitiria compor uma história da filologia ligada à história da cultura e dos sentidos (CORBIN, 1998, p. 109). o

15 Um procedimento crítico que se combina com o da lectio difficilior potior é o da emendatio ope conjecturae, a que se recorre quando a documentação é insuficiente ou ambígua; em história, essas lacunas na documentação obrigam o historiador a se valer do modo dubitativo, em que abundam os "talvez", os "pode ser" etc. Qual problema há em se recorrer a esse modo de articulação do discurso histórico e filológico? Atenhamo-nos, em primeiro lugar, à discussão histórica, pois ela servirá para lançar luz sobre aquela propriamente filológica. Em seu belo livro, O retorno de Martin Guerre, Natalie Zemon Davies narra o caso de um homem que é substituído por outro no seio de sua família, que é acolhido pela esposa como se fosse o verdadeiro marido, e que, ao final, é "desmascarado", processado, inquirido e condenado. Mas é mais do que essas vidas, a do verdadeiro e do falso Martin Guerre e de "sua" esposa, o que interessa a Natalie Zemon Davies; ela deseja compreendê-las integradas ao mundo camponês da França do século XVI a que pertencem. Como produz essa compreensão e essa integração? Partamos de uma observação de Natalie Zemon Davis, presente no "Prefácio" de seu livro, e de um comentário a uma outra observação sua, de caráter análogo e complementar, referida por Carlo Ginzburg, em que um modo de fazer história principia a se delinear: 1. "Ao observar Gérard Depardieu representando o papel do falso Martin Guerre, surgiram-me novas ideias de como pensar o desempenho do verdadeiro impostor, Arnaud de Tilh. Senti que tinha meu próprio laboratório histórico que gerava, não provas, mas possibilidades históricas" (DAVIS, s. d., p. 10); 2. "Pelo contrário - diz Natalie Davis - foi precisamente no decurso do trabalho de filme, ao ver 'na fase de montagem Roger Planchon a experimentar variadas entoações para o papel do juiz (Coras), que me pareceu ter à minha disposição um verdadeiro e apropriado laboratório historiográfico, um laboratório em que a experimentação não produzia provas irrefutáveis, mas sim possibilidades históricas' (p. X)" (GINZBURG, 1991d, p. 180). Carlo Ginzburg (1991d, p. 180), ao interpretar o que significaria, no enunciado de Natalie Zemon Davis, "laboratório historiográfico", assevera que a expressão tem um necessário sentido metafórico, pois as "experiências" laboratoriais estão vedadas ao historiador, que estuda "fenômenos temporalmente irreversíveis 'enquanto tais'". A impossibilidade de recorrer à experimentação não é impedimento, no entanto, para que a história, assim como a paleontologia, por exemplo, crie "critérios de cientificidade sui generis fundados, para a consciência comum, sobre a noção de prova" (GINZBURG, 1991d, p. 180). Mas se assim é - e discutiremos, à frente, como a noção de "prova" é constituída no livro de Natalie Zemon Davis -, é preciso, por outro lado, interpretar melhor os excertos acima apresentados, em que se circunscreve um sentido possível e mais preciso de "laboratório historiográfico", pois dele se fala perante a performance de dois atores, Gérard Depardieu e Roger Planchon. Ao observar este último a experimentar variadas entonações de voz para compor sua caracterização do juiz Coras - o responsável pelo caso "Martin Guerre" -, foi que Natalie Zemon Davies teve uma espécie de insight, pois do que vira e ouvira lhe pareceu ter à sua disposição "um verdadeiro e apropriado laboratório historiográfico, um laboratório em que a experimentação não produzia provas irrefutáveis, mas sim possibilidades históricas"; é claro que a performance dos atores lhe aguçou a consciência do limiar da verossimilhança de todo discurso sobre o passado, e assim como um ator, em um filme de caráter histórico, tenta reconstruir a historicidade do caractere por ele representado, sempre de forma tateante, e, na maior parte dos casos, anacrônica - pois é impossível, por exemplo, evitar a fratura irremediável ocasionada pela historicidade do próprio sistema linguístico, estando o francês de outrora perdido para nós sem a possibilidade de que se opere uma sua reversão, e, nesse sentido, toda fala em um filme histórico está marcada pelo seu desajuste histórico -, também o historiador produz, por meio do seu discurso sobre o passado, possibilidades históricas mais do que certezas irrefutáveis. Mas é curioso que seja justamente diante das entonações variadas que Robert Planchon empresta a sua voz para compor o caráter de Coras que Natalie Zemon Davies tenha seu insight, pois o próprio e inevitável anacronismo da voz do ator, incapaz de capturar sub modo historico a voz dos mortos a que quer emprestar vida, evidencia que essas entonações estão fora do que se compreende como "possibilidades históricas". O ator, ao tentar emprestar voz à sua personagem, se vale de um antigo tropo, a prosopopeia, e é ela que funda a emendatio ope conjecturae dos filólogos neolachmnnianos, que põem a falar o morto emprestando-lhe a voz que ajuízam a mais apropriada para a composição do caractere que desejam ressuscitar. Há, no livro de Natalie Zemon Davis, o recurso ao que Carlo Ginzburg chama de "indagação judiciária", e isso em um 
sentido, o texto como "evento" perde, quando da crítica filológica neolachmanniana, parte de sua singularidade, pois que esta se dissolve na continuidade ideal do stylus - essa força primordial - que a crítica filológica produz quando da fixação do texto como resultante da "crença". Essa fixação parece fundar-se no mais absoluto objetivismo histórico, sem que haja a consciência de que a pretensa isenção é nada menos do que o entendimento estético do editor elevado à condição de norma confessa, mas a do outro cujos direitos são restaurados quando o filólogo lhe restitui o flatus vocis.

A edição crítica do texto à maneira neolachmanniana fixa o texto e sua significação, pois crê legítima sua determinação pela "unidade de intenção" que o filólogo não tem dificuldade em reconhecer e em especificar. Nesse sentido, toda operação filológica é a repetição de um mesmo problema e de uma mesma pergunta, de que se espera uma mesma resposta, que denega o que é próprio do fazer histórico e filológico: "Elaborar um fato é construir. Se se quiser, é fornecer uma resposta a uma pergunta. E se não há pergunta, só há o nada" - o nada da tautologia metódica. As teorias filológicas de cunho lachmanniano e neolachmanniano são modelizações sobre a arte de fixar criticamente textos, não só poéticos e fictos, é preciso dizer, e consignam por meio das categorias que operacionalizam o método uma suposta racionalidade científica; estas sempre se apresentam como principios formulados do saber filológico, redundantes de pesquisas efetuadas, mas que foram paradoxalmente modelizadas por esses princípios; essa circularidade do procedimento crítico deve ser considerada um pressuposto não explicitado e que sempre se pensou "natural". Uma pergunta que cabe fazer é como esse pressuposto se tornou altamente consensual no pensamento e na prática filológicos. Como resultante, quase não há reflexão sobre

duplo sentido: 1. Primeiramente, ao recorrer ao discurso de Coras sobre o caso "Martin Guerre", ela não pode se esquivar ao reconhecimento de certa contiguidade entre a ótica do juiz e a sua própria, já que a reconstituição de vidas de homens e mulheres de condição não privilegiada, como o são o falso Martin Guerre e sua mulher, depende normalmente de "actas provenientes de tribunais leigos ou eclesiásticos", e, nessas situações, "o historiador tem a impressão de efectuar uma indagação por interposta pessoa, a do inquiridor ou a do juiz" (GINZBURG, 1991d, p. 181). É a indagação de caráter judiciário levada a termo por Coras que tinge do mesmo tom parte do discurso histórico do livro de Natalie Zemon Davies; mas, e quanto àquilo que está ausente do discurso de Coras e que a historiadora quer inserir em seu próprio discurso? 2. Se a reconstituição das vidas do falso Martin Guerre e de sua "esposa", Bertrande, depende de escritos que foram produzidos diante de uma ocorrência excepcional, e se são, em suma, provas de caráter quase que judiciário, pois uma delas foi composta pelo juiz que acompanhou o processo, Coras, essa reconstituição, para ser mais ampla, como já se disse, depende da conjugação de provas de outra natureza àquelas propriamente concernentes ao "caso". Carlo Ginzburg (1991d, p. 183), ao falar do emprego de uma documentação complementar por Natalie Zemon Davis para recompor as vidas do falso Martin Guerre e de Bertrande, assevera que "é precisamente o carácter excepcional do caso Martin Guerre que lança luz sobre uma normalidade documentalmente imprecisa"; mas de que maneira a documentação respeitante aos camponeses franceses do século XVI é documentalmente imprecisa em sua "normalidade"? Pode-se dizer que a "normalidade" da documentação deriva do fato de nela haver situações análogas e é a analogia condição, por repetibilidade, de se poder falar, inclusive, de "normalidade"; é o recurso à analogia cumulativa presente na documentação complementar que permite a Natalie Zemon Davis, como o diz o próprio Carlo Ginzburg (1991d, p. 183), "preencher as lacunas do acontecimento", que ela "se propôs reconstruir". A própria Natalie Zemon Davis esclarece-nos sobre seu procedimento de reconstituição dessas vidas: "Quando não encontrava o homem ou a mulher que estava a procurar, voltava-me na medida do possível para outras fontes do mesmo tempo e lugar para descobrir o mundo que eles devem ter conhecido e as reações que podiam ter tido. Se aquilo que apresento é em parte invenção minha, está no entanto solidamente ancorado às vozes do passado" (GINZBURG, 1991d, p. 183). É preciso dizer agora que se a excepcionalidade da vida do falso Martin Guerre e de Bertrande pode lançar "alguma luz sobre a normalidade documentalmente imprecisa" com que deparamos quando compulsamos documentos de natureza serial concernentes aos camponeses da Europa moderna, por outro lado como é possível contar justamente com a "normalidade documentalmente imprecisa" dessa mesma documentação para recompor um largo setor do vivido que se reputa, sub-repticiamente, "normal"? A excepcionalidade do caso Martin Guerre está evidente em uma questão com que Natalie Zemon Davis abre o seu livro: "Será que alguns aldeões individualmente nunca tentaram modelar sua vida de formas insólitas e inesperadas?" (DAVIS, s. d., p. 17). Natalie Zemon Davis toma como prova para a reconstituição das vidas camponesas dos Guerre e de Arnaud de Tilh, para a reconstituição do cotidiano de seu mundo, documentos que se reputam tão normais, ou seja, tão recorrentes no grupo a que concernem, que se pode conjecturar que sejam válidos para todos aqueles que pertençam ao mesmo grupo. Essa prova se funda, no entanto, na analogia, na conjectura. Poderíamos nos perguntar agora: qual é o limite da validade da analogia na depreensão da documentação daquilo que me interessa saber? Quando extraio de documentos dados informativos que penso concernirem aos Guerre e a Arnaud de Tilh, conquanto esses documentos não tenham sido produzidos diante deles, qual a pertinência dessa inter-relação e da extrapolação dos dados documentais para iluminar realidades outras? O que está em questão aqui é a própria prova e o recurso a uma prosopopeia indireta, em que se toma emprestada a voz de um morto, mas para fazer um outro defunto falar; é, filologicamente, um procedimento análogo ao da conjugação de lições para produzir por meio dela a restitutio textus. 
questões de interação e combinação de campos e modos diversos de conhecimento, sobretudo histórico e filológico, em que aquele elucide este. Parte-se sempre de um pressuposto, o de que exista algo chamado "filologia", "como uma realidade pronta e completa fora da consciência humana, que só precisa ser apreendida e apropriada, cognitivamente, por esta" (RÜSEN, 2001, p. 67), quando, na verdade, seria preciso evadir-se da fácil tendência a essa representação com o objetivo de se evitar a determinação de um domínio de conhecimento e de seu conteúdo previamente a toda pesquisa a realizar. Jörn Rüsen, no primeiro volume de sua obra sobre historiografia, assevera que:

[...] as histórias fundamentam sua pretensão de validade ao expor que os acontecimentos que narram efetivamente ocorreram do modo narrado. Isso se dá, no mais das vezes, pelo fato de que as histórias indicam suas fontes, mencionam testemunhas e avalistas, o narrador explicita sua condição de testemunha ocular - em suma: mediante uma série de expressões linguísticas que designam a experiência sobre a qual se baseia o conteúdo factual da história. A verdade histórica pode ser caracterizada, nessa perspectiva de fundamentação, como pertinência empírica. Histórias são empiricamente pertinentes quando os fatos narrados estão garantidos pela experiência (RÜSEN, 2001, p. 91).

Mas como pode ser possivel que o narrado equivalha à ocorrência dos acontecimentos, se sabemos que estes são sempre apreendidos "de forma incompleta e lateralmente" (VEYNE, 1998, p. 18) por procedimentos que implicam a seleção, simplificação e organização do que se narra como condição mesma de que se o narre? E como pode a realidade histórica ser caracterizada como portadora de "pertinência empírica", se os fatos narrados normalmente não estão garantidos pela experiência, e, mesmo que o estivessem, cada testemunha gera apenas uma perspectiva do evento, não podendo apreendê-lo em sua totalidade? Se a história só se faz por meio de documentos, se ela se constrói por meio de indícios (VEYNE, 1998, p. 18), por que devemos pensar que todos os indícios são sempre parte integrante de uma unidade superior, sem nos perguntar se essa unidade que os determina é ela própria historicamente pertinente ou não? Paul Veyne declara que mesmo que ele tivesse sido Napoleão, teria "apenas uma perspectiva sobre o que os historiadores chamarão o evento Waterloo", e que a narração histórica, baseada em indícios, em documentos, está "além de todos os documentos, já que nenhum deles pode ser o próprio evento": que conclusões tirar disso para a prática filológica? Creu-se e crê-se que os testemunhos de uma dada tradição não equivalham ao texto genuíno saído das mãos do autor; ele está para além de todos os testemunhos que o transmitem; a história, mesmo que narrada a partir de documentos, de indícios, "não mostra o passado ao vivo, 'como se você estivesse lá" (VEYNE, 1998, p. 24), pois ela é diegesis, e não mimesis, com tudo o que isso implica; a filologia, ao contrário, buscou sempre produzir efeitos retóricos, ao querer fazer seu personagem falar em primeira pessoa, e é o ethos o que ela nos apresenta quando quer dar vida à sua trama: pensou-se que a operação filológica de restitutio textus pudesse fazer falar o autor eliminando do texto toda mediação, com exceção daquela que no presente elide todas as outras, passadas. Jörn Rüsen (2001, p. 92) fixa como ponto de partida de uma história uma orientação determinadora de sentido, "ideia", que se "constitui simultaneamente como instância suprema decisiva para a verdade de uma história"; esta o manifesta "na medida em que expõe esse critério de sentido por 
recurso [...] aos elementos do senso comum previamente dados na orientação do tempo, percebidos por seus destinatários como acima de qualquer dúvida", o que parece ter sido o caso para a crença na eficácia da mimese e da prosopopeia filológicas. A crítica filológica parece ter crido na possibilidade de reforçar sua pertinência empírica ao remeter seus leitores a instâncias de autenticação: mas que instâncias são essas? Pode-se pensar que essa instância consiste na "contemporaneidade factual do passado, ou seja, no fato de que subsiste algo dele e que dá testemunho dele" (RÜSEN, 2001, p. 101), como, por exemplo, os testemunhos constituintes de uma dada tradição textual. Se há contemporaneidade factual do passado, só há aquela de uma prática, a de se registrar por escrito algo que, ao ser registrado, se torna "texto". Entretanto, é preciso ainda se perguntar se a pragmática de registro é a mesma dos dias de hoje; é preciso saber quem registrava o que registrava, e o porquê do registro; é preciso saber o que se fazia com o registro depois de produzido; é preciso saber se o registro, se a inscrição, é o resultado final de uma operação escriturária ou se é o indício de algo diferente, como a voz; se o registro o é de uma ou mais vozes, e se a modalidade de existência do que em dado momento se tornou objeto de inscrição é a voz e o corpo, quem eram os executantes, os performers?; como se executava a performance?; como a voz colidiu com a escritura ou como convergiu para ela?; qual a relação da voz e da escritura com um dado costume poético? Mesmo que haja indícios, como os testemunhos de uma dada tradição textual, não há contemporaneidade factual do passado, pois para que haja tal contemporaneidade, é preciso entender o indício à luz desse passado de que ele é apenas fragmento, que pode auxiliar na compreensão histórica e filológica que dele se deseja produzir, mas que pode não bastar para tanto; não pode haver contemporaneidade factual do passado pela simples existência de indícios, porque indícios não são autoevidentes. E cabe dizer ainda que os registros, se são objeto de alguém, não são necessariamente de um autor tal como o compreendemos, o que torna sua interpretação à luz dessa categoria enganosa se levada a termo sem prévia pesquisa histórica ${ }^{16}$.

\section{Philology AND historiographical field (OR A CRitigue to Method)}

Abstract: The aim of this paper is to criticize philological methods starting from establishing a critical relationship between philology and historiography.

Keywords: Philology. Historiography. Critique. Philological methods.

\section{REFERÊNCIAS}

BOURDIEU, P.; CHARTIER, R. A leitura: uma prática cultural. In: CHARTIER, R. (org.). Práticas de leitura. São Paulo: Estação Liberdade, 1996. p. 231-253.

\footnotetext{
16 A prática filológica de fixação de textos, visando a alguns fins específicos entre os praticantes do lachmannismo e do neolachmannismo, que requer método de análise específico, é uma forma de evidência de representações constitutivas de um dado grupo social, o dos filólogos, pois as operações da ars critica são forma de "produção" no presente, por meio de atualização, não apenas de bens simbólicos de grupos passados, mas sobretudo de bens culturais tornados presentes quando de sua apropriação, que fala mais dela, da apropriação, e dos homens que a operacionalizam, do que propriamente do passado. Esse será um dos vieses de nossa pesquisa (PROST, 1998, p. 129).
} 
CASTRO, I. O retorno à filologia. In: CASTRO, I. Miscelânea de estudos linguísticos, filológicos e literários in memoriam Celso Cunha. Rio de Janeiro: Nova Fronteira, 1995. p. 511-520.

CASTRO, I. Filologia. In: Biblos. Enciclopédia Verbo das Literaturas de Língua Portuguesa. Lisboa: Verbo, 1997a. v. II, p. 602-610.

CASTRO, I. Os ossos de Camões. In: ENCONTRO NACIONAL DA ASSOCIAÇÃO PORTUGUESA DE LINGUÍSTICA, 12., 1997, Lisboa. Actas [...]. Lisboa: Associação Portuguesa de Linguística, 1997b. v. II, p. 403-409.

CHARTIER, R. Escribir las prácticas. Foucault, De Certeau, Marin. Buenos Aires: Manatial, 1996.

CHARTIER, R. "A quimera da origem”. Foucault, o Iluminismo e a Revolução Francesa. In: CHARTIER, R. À beira da falésia: a história entre certezas e inquietude. Porto Alegre: Editora UFRGS, 2004. p. 123-150.

CHARTIER, R. Estratégias e táticas. De Certeau e as "artes de fazer". In: CHARTIER, R. À beira da falésia: a história entre certezas e inquietude. Porto Alegre: Editora UFRGS, 2002. p. 151-161.

CORBIN, A. Do Limousin às culturas sensiveis. In: SIRINELLI, J.-F.; RIOUX, J.-P. (org.). Para um história cultural. Lisboa: Estampa, 1998. p. 97-110.

DAVIS, N. Z. O retorno de Martin Guerre. Rio de Janeiro: Paz e Terra, [s. d].

DIONíSIO, J. Com o mesmo nome: sobre o pensamento filológico de Ivo Castro. In: ÁLVAREZ, R. et al. Ao sabor do texto: estudos dedicados a Ivo Castro. Santiago de Compostela: Universidade de Santiago de Compostela, 2013. p. 125-136.

DOSSE, F. Paul Ricoeur y Michel de Certeau: la historia entre el decir y el hacer. Buenos Aires: Nueva Visión, 2009.

FEBVRE, L. De 1892 a 1933: exame de consciência de uma história e de um historiador. In: FEBVRE, L. Combates pela história. Lisboa: Presença, 1989. p. 15-27.

GINZBURG, C. O nome e o como. Troca desigual e mercado historiográfico. In: GINZBURG, C. A micro-história e outros ensaios. Lisboa: Difel, 1991a. p. 169-178.

GINZBURG, C. Ekphrasis e citação. In: GINZBURG, C. A micro-história e outros ensaios. Lisboa: Difel, 1991b. p. 215-232.

GINZBURG, C. O inquisidor como antropólogo: uma analogia e suas implicações. In: GINZBURG, C. A micro-história e outros ensaios. Lisboa: Difel, 1991c. p. 203-214.

GINZBURG, C. Provas e possibilidades à margem de "Il retorno de Martin Guerre", de Natalie Zemon Davis. In: GINZBURG, C. A micro-história e outros ensaios. Lisboa: Difel, 1991d. p. 179-202.

GOULEMOT, J. M. Da leitura como produção de sentido. In: CHARTIER, R. (org.). Práticas de leitura. São Paulo: Estação Liberdade, 1996. p. 107-116.

HANSEN, J. A. Agudezas seiscentistas. Floema: Caderno de Teoria e História Literária, Vitória da Conquista, v. 2A, p. 85-109, 2006.

HUIZINGA, J. El concepto de la historia. México: Fondo de Cultura Económica, 1994. 
JAKOBSON, R. Langage en opération. Paris: Hermann, 1964. p. 269-281.

JAUSS, H. R. A história da literatura como provocação à teoria literária. São Paulo: Ática, 1994.

KUHN, T. As estruturas das revoluções científicas. São Paulo: Perspectiva, 2017.

POMIAN, K. História cultural, história dos semióforos. In: SIRINELLI, J.-F.; RIOUX, J.-P. (org.). Para uma história cultural. Lisboa: Estampa, 1998. p. 71-95. PROST, A. Social e cultural indissociavelmente. In: SIRINELLI, J.-F.; RIOUX, J.-P. (org.). Para uma história cultural. Lisboa: Estampa, 1998. p. 123-137.

RÜSEN, J. Razão histórica. Teoria da história: os fundamentos da ciência histórica. Brasília: Editora UnB, 2001.

SIRINELLI, J.-F.; RIOUX, J.-P. (org.). Para uma história cultural. Lisboa: Estampa, 1998. p. 123-137.

SPINA, S. Introdução à edótica. São Paulo: Cultrix: Edusp, 1977.

VEYNE, P. Como se escreve a história. Brasília: Editora UnB, 1998.

ZUMTHOR, P. Performance, recepção, leitura. São Paulo: Cosac Naify, 2014. 